\title{
Hepatozoon canis (JAMES, 1905) EM CÃES DE UBERLÂNDIA, MINAS GERAIS. RELATO DE DOIS CASOS.
}

\author{
HEPATOZOON CANIS (JAMES, 1905) IN DOGS FROM UBERLÂNDIA, MINAS \\ GERAIS. REPORTS OF TWO CASES.
}

\section{RESUMO}

Gametócitos de Hepatozoon canis, medindo 9,56 im x 5,60(im, foram identificados no citoplasma de leucócitos circulantes de dois cães atendidos no Hospital Veterinário da Universidade Federal de Uberlândia. Essa hemoparasitose ocorreu associada à infecção por E. canis. É relatada a primeira ocorrência do H. canis em Uberlândia, Minas Gerais.

UNITERMOS: Hepatozoon canis; Cães; Minas Gerais

\section{INTRODUÇÃO}

O Hepatozoon é um protozoário da família Hemogregariniidae Neveau-Lemaire 1910, que parasita os leucócitos e hemácias de animais domésticos e silvestres, tendo sido descrito em répteis, aves, marsupiais, insetívoros, ungulados e mamíferos. Entre eles, os roedores têm sido os mais comumente infectados4. É heteroxeno, apresentando o ciclo evolutivo tí pico dos coccídios, com a fase sexuada e de esporulação nos hospedeiros invertebrados e a esquizogonia e gametogonia nos vertebrados. $O$ carrapato $R$ hipicephalus sanguineus é o transmissor deste hemoparasito. $O$ cão toma-se infectado pela ingestão do ixodídeo contendo os oocistos esporulados59 10>u.

Os esporozoítos são liberados no intestino, atravessam o epitélio intestinal e alcançam a veia porta, chegando até o fígado, onde a maioria passa dos capilares aos hepatócitos e células de Kupffer, multiplicando-se por esquizogonia. Podem também atingir o baço, medula óssea, pulmões, linfonodos ou miocárdio onde também ocorre a multiplicação. Parece que há dois tipos de esquizontes. Um contendo macromerozoítos e outro micromerozoítos. Estes são fagocitados pelos neutrófilos e monócitos tomando-se gametócitos 5,s. Os gametócitos são as formas do parasito encontradas no sangue periférico dos cães. São formações alongadas ou em bastão que se coram pelos derivados de Romanowsky que tomam o citoplasma claro e o núcleo arroxeado.

A ocorrência do Hepatozoon spp tem sido relatada em diver sos países; E.U.A., Itália, índia, Israel, França, Portugal, Áfri

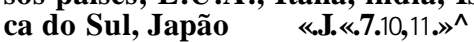

Objetiva-se com o presente relato, descrever o encontro de Hepatozoon canis em dois cães atendidos no Hospital Vete rinário da Universidade Federal de Uberlândia.

\section{RELATO DE CASOS}

Primeiro Caso: Cadela mestiça, 3 meses de idade, admitida em outubro/1991. Ao exame clínico revelou: aumento de temperatura $\left(41^{\circ} \mathrm{C}\right)$, mucosas oculares hiperêmicas, apatia, prostração, corrimento ocular e nasal sero-mucoso, estertores úmidos nos pulmões, fígado aumentado de volume e sensível à palpação. $O$ animal estava infestado por Rhipicephalus sanguineus. O exame coproparasitológico e a pesquisa de corpúsculos de Lentz deram resultados negativos. Pelo hemograma detectou-se anemia do tipo normocítica normocrômica e um desvio para a esquerda. O exame do esfregaço sanguí neo, corado pelo May - Grunwald - Giemsa, revelou no citoplasma dos leucócitos (neutrófilos e monócitos) dois tipos de formações:

- formações alongadas, com citoplasma róseo-claro envolto por uma membrana, núcleo vermelho bem definido, localiza do mais próximo a uma das extremidades, medindo 8,90 |i.m 9,89 jim x 4,0 $\operatorname{im}-6,9 \wedge . m(x=9,56$ um x $5,60 \wedge m)$, e que foram identificadas como gametócitos de Hepatozoon canis (Fig. 1 e 2).

- formações arredondadas, de coloração azul arroxeada e com granulações bem evidentes, identificadas como mórulas de Ehrlichia canis (Fig. 2).

Segundo caso: Cadela Pastor Belga, 11 meses de idade, admi tida em novembro/1991. Ao exame clínico revelou: aumento de temperatura $\left(40,1^{\circ} \mathrm{C}\right)$, mucosas visíveis hiperêmicas, caquexia, desidratação intensa, dispnéia, taquicardia, estertores úmidos nos pulmões, sensibilidade renal à palpação, incoordenação dos membros posteriores, morrendo um dia após o atendimento. $O$ exame coproparasitológico c a pesqui sa de corpúsculos de Lentz mostram-se negativos. O hemograma revelou leucocitose com neutrofilia e um desvio para a esquerda. $O$ exame da camada leucocitária revelou presença de Ehrlichia canis em monócitos e gametócitos de Hepatozoon canis em neutrófilos.

\section{DISCUSSÃO E CONCLUSÕES}

Nos dois casos de infecção por $H$. canis associado à E. canis os sinais clínicos observados foram: anorexia, aumento de temperatura, mucosas hiperêmicas, estertores úmidos nos pul mões, taquicardia. Estes sinais e outros como letargia, palidez de mucosas, linfadenopatia, emaciação, corrimento nasal e ocular, diarréia com sangue, paralisia lombar, dermatose e

3 - Técnico de Laboratório-Universidade Federal de Uberlândia 
MUNDIM, A. V.: JACOMINI, J. O.; MUNDIM, M. J. S.; ARAUUJ, S. F. Hepatozoon canis (James, 1905) cm cäes de Uberlândia, Mnas Gerais. Relato de dois casos. Braz. J. vet. Res. anim. Sd., Sĩo Paulo, v.29, p. 359-361, 1992. Suplemento.

algumas vezes morte foram encontradas por vários autores 3.5 . $6,7,8,11,12,13, \mathrm{~cm}$ cães infectados pelo Hepatozoon, com infecçăo única ou mista. Os danos causados aos căes pelo Hepatozoon eståo ainda pouco clucidados. Alguns autores consideram o protozoário como pouco patogênico c oportunista, aparecendo associado com outras infecçðes como crliquiose, babesiose, dirofilariose, cinomose, leishmaniose, demodicose entre outras 1,2,4,5,6,7,10. Outros autores já o consideram como patogênico, causando sintomatologia nos căcs, podendo ser fatal.

Nos casos relatados, o Hepatozoon apareceu associado com Ehrlichia canis, mascarando assim a sintomatologia.

O grau de parasitemia para o H. canis foi baixo em tomo de $1,0 \%$ das células parasitadas nos dois cãcs. Alguns autores rclatam o grau de parasitemia encontrado por cles, variando de $0,8 \%$ a $17,0 \%$. 5 .

Fica assim rcgistrado o primeiro relato de Hepatozoon canis cm Ubcrlândia, no Estado de Minas Gerais.

\section{SUMMARY}

Hepatozoon canis gamclocytes, measuring $9.56 \mu \mathrm{m} \times 5.60$ $\mu \mathrm{m}$ were identified in circulating leukocytes of two dogs admitted to the Veterinary Hospital of the Universidade Federal de Uberlândia. Morulac of Ehrlichia canis were also found in circulating monocytes. The authors report the first occurrence of $\mathbf{H}$. canis in Ubcrlândia, Minas Gerais state.

UNITERMS: Hepatozoon canis; Dogs; Minas Gcrais; Brazil

\section{REFERÊNCIAS BIBLIOGRÁFICAS}

01-ARRU,E.; PAU, S.; LEONI, A. Segnalazione di Hepatozoon canis in Sardegna. Riv. Parassit., v.43, p. 57-62, 1982.

02-BANSAL, R.; GAUTAM, O. P.; BANERJEE, D. P. Prevalence of Babesia canis and Hepatozocon canls infection in dogs of tisssar (Haryana) and Delhi and attemps to isolatc Babesia from human beigns. Indian vet. J., v.62, p. 748-51, 1985.

03-BARTON, C. L.; RUSSO, E. A.; CRAIG, T. M.; GREEN, R. W. Canine hepatozoonosis: a retrospective study of 15 naturally occurring cases. J. Amer. Anim. Hosp. Ass, v.21, p. 125-34, 1985.

04-BEAUFILS, J. P.; MARTIN-GRANEL, J.; BERTRAND, F. (Canine hepatozoonosis. 2. Report on 28 cases). Hepatozoonose canine. 2. A propos de 28 cas. Prat. Méd. Chl. An. Comp. v.23, p. 281-93, 1988 .

05-CRAIG, T. M.; SMALLWOOD, J. E.; KNAUER, K. W.; McGRATH, J.P. Hepatozoon canls infection in dogs: clinical, radiographic and hematologic findings. J. Amer. Vet. Med. Ass., v.173, p. 967-72, 1978.

06-ELIAS, E.; HOMANS, P. A. Hepatozoon canis infection in dogs: clinical and hacmatological findings; treatment. J. small anim. Pract., v.26, p. 55-62, 1988.

07-MAKIMURA, S.; KINJO, H.; MATOVELO, J. A.; OGAWA, H.; YAMASAKI, K.; MATSUYAMA, K.;TATEYAMA,S.;USUI, M. Threc cases of Hepatozonn canis infoctionof choss in Miyazaki Prefecturc. J. Japan Vet. Med. Ass., v.44, p. 928-32, 1991.

08-NORDGREN, R. M.; CRAIG, T.M. Experimental transmission of the Texas strain of Hepatozoon canis. Vet. Parasitol., v.16, p. 207-14, 1984.

09-OLSEN, O. W. Parasitologla anlmal. 3. cd. Barcelona, Editorial Acdos, 1977. v.1, p. 185-90.

10-PENZHORN, B.L.; LANGE, A. L. Hepatozoon and Ehrlichig in the same canine neutrophil. Tydskr.S. Afr. vet. Ver, v.61,p. 95, 1990.

11-REBELO, M. E. Hepatozoon canis (James, 1905) cm canídeos domésticos na zonado Alto Douro Concelho de Alij6. Rep. Trab. L. I. N. V., v.21, p. 99-102, 1989.

12-URQUHART, G. M.; ARMOUR, J.; DUNCAN, J. L.; DUNN, A. M.; JENNINGS, F. W. Parasitologia veterinária. Rio de Janciro, Guanabara Koogan, 1990. p. 255.

13-VERCRUYSSE, J.; PARENT, R. Notc sur deux cas d hépatozoonosc canine a Dakar. Rev. méd. Vét., v.133, p. 183-5, 1982.

Reccbido para publicação cm 19/03/1992 Aprovado para publicação cm 08/07/1992 


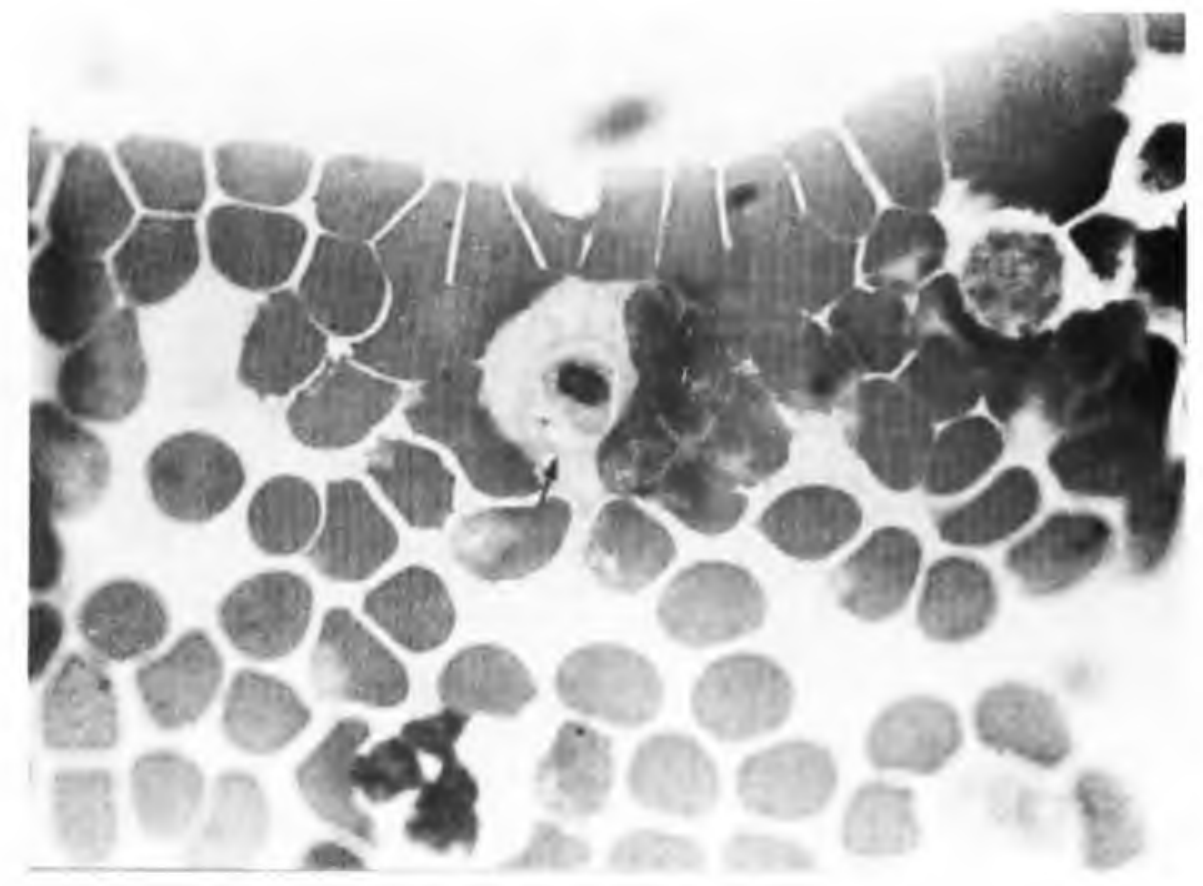

HKII RA I

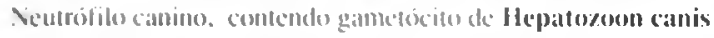

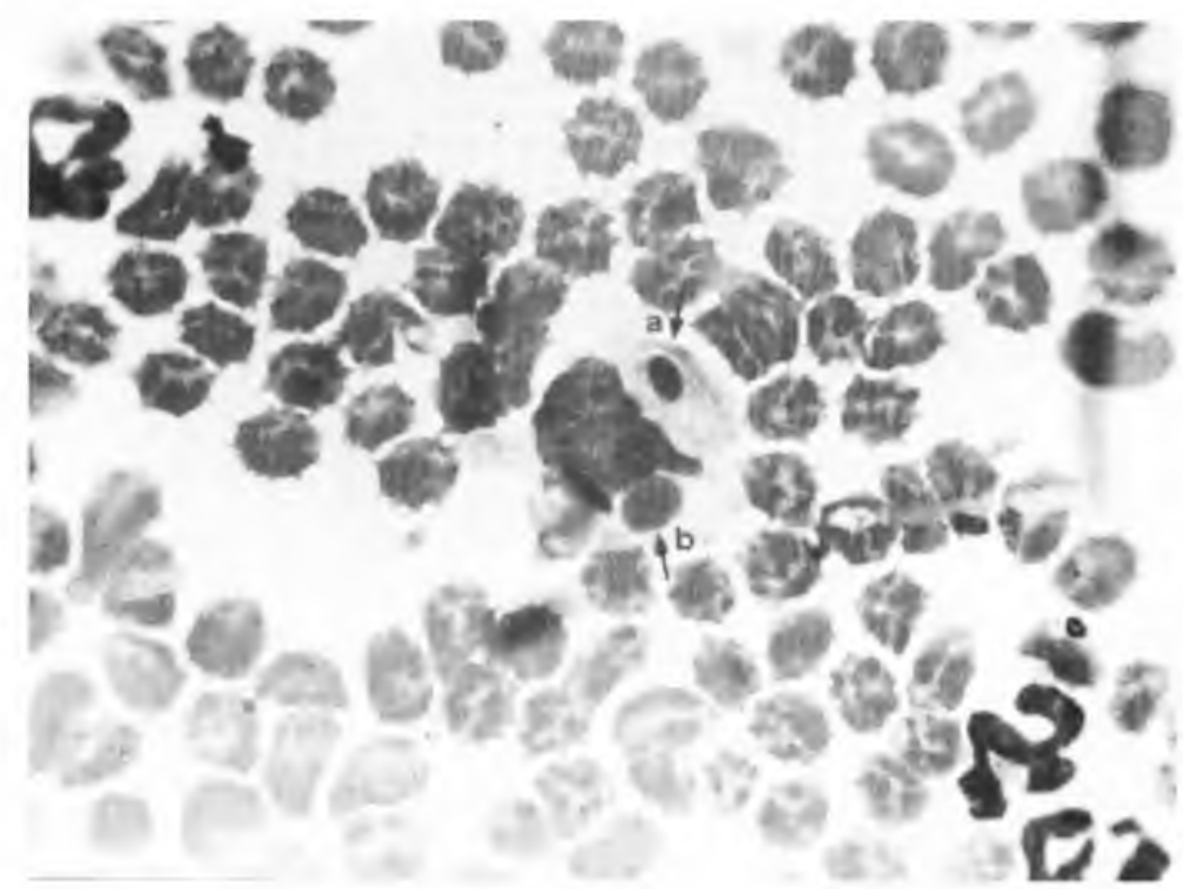

HICIRA 2

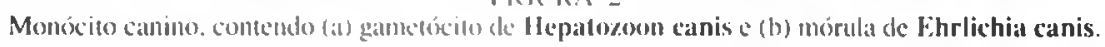

